\title{
Introducing Teaching Personal and Social Responsibility into physical education
}

The Teaching Personal and Social Responsibility (TPSR) model is a values-based sport and physical activity pedagogical model that has been used by practitioners around the world in a variety of settings such as physical education and community sport programmes (Lee \& Choi, 2015; Walsh, Veri, \& Willard, 2015; Wright, Jacobs, Ressler, \& Jung, 2016). When used in physical education TPSR simultaneously promotes teaching and learning around both social and personal development and physical education curriculum goals. TPSR focuses on students achieving five major goals (often described as levels). These are described as respect (Level 1), participation and effort (Level 2), self-direction (Level 3), caring and leadership (Level 4) and transfer of the various goals to other contexts (Level 5). A TPSR-based lesson generally begins with relational time where teachers build relationships with their students and encourage learners to establish and build relationships with each other. This is followed by a group awareness talk where teachers focus students' learning on the group goals for the day, both TPSR and physical education related, and outline what will be covered in the lesson. The physical activity content of the class is then taught using a variety of pedagogical approaches designed to generate learning around the physical education curriculum and the TPSR related goals. These pedagogical approaches include giving students choices, peer teaching, cooperative activities and allowing students to increasingly take responsibility for their learning. The class concludes with a group meeting and reflection time where students provide feedback on the lesson, reflect on the goals of the day and their own behavior during the lesson in relation to these goals. This time is also used to discuss the transferability of these lessons to their family, school, and community settings (Hellison, 2011; Hellison et al., 2000).

TPSR has a strong connection with social and emotional learning (SEL), an area that has become more visible in curricula internationally over recent years with Scotland, Singapore, New Zealand and the USA as examples of countries which have identified SEL as central to their vision of learning into the future. In many of these countries, physical education has been identified as an important learning area for achieving SEL and TPSR, when implemented well, has been found to be effective in doing so (Gordon, Jacobs, \& Wright, 2016). 
Australia has also identified SEL through the Australian Curriculum in the Health and Physical Education learning area's sub-strand of "Communicating and Interacting for health and wellbeing" (Australian Curriculum, 2015) and the General Capability of Personal and Social Capability where the writers note that,

In the Australia Curriculum: Health and Physical Education, students work independently and collaboratively in movement- and non-movement-based activities to develop personal and social skills as well as an awareness and appreciation of their own and others' strengths and abilities. (General Capabilities in the Australian Curriculum: Health and Physical Education, 2015)

Health and Physical Education in the Australian Curriculum has been shaped by the identification of five interrelated propositions informed by a strong and diverse research base for a futures-oriented curriculum. It should be noted that all five propositions are aligned with the goals of TPSR. TPSR has a focus on educating students around SEL, it is fundamentally a strength-based approach and it values movement both as a means to generate teaching and learning around personal and social responsibility and for the inherent value of improved movement competence. The development of understanding around personal responsibility for health is aligned with Health literacy and the encouragement for students to take action to promote personal health and the wellbeing of others. A high fidelity TPSR programme also engages students in critical inquiry processes which are central to learners developing understanding of the contextual factors that influence their lives and impact their decision making around health and wellbeing. Readers who are interested in exploring the five propositions will find greater detail through the following link:

http://www.australiancurriculum.edu.au/health-and-physical-education/key-ideas. A similar situation exists in New Zealand where the New Zealand Curriculum supports TPSR through the key competencies, which include managing self and relating to others, and the essence statement for physical education which states that students:

Through learning and by accepting challenges in health-related movement contexts, students reflect on the nature of well-being and how to promote it. As they develop resilience and a sense of personal and social responsibility, they are increasingly able to take responsibility for themselves and contribute to the well-being of those around them, their communities, environments, and society. (Ministry of Education, 2007, p. 16) 
teaching is generally positive with a national survey finding that many teachers continued to use the model over a number of years. The teachers found TPSR led to more successful teaching and learning in physical education, improvement in the students levels of responsibility while at the same time improving the culture of the classroom (Gordon, Thevenard, \& Hodis, 2011).

For teachers considering introducing TPSR into their classrooms there can be, understandably, some level of trepidation. Two USA based studies give insight into the process. In the first study seven undergraduate students participated in a college evaluation course designed around Hellison's TPSR Model. The students had little to no pedagogical background and no experience with TPSR. All students described themselves as knowledgeable and competent in physical activity. The course met twice a week for fifteen weeks. Initially, the students were assigned to read Hellison's (2011) Teaching Personal and Social Responsibility Through Physical Activity along with guided discussion questions. In addition, the students were introduced to the Tool for Assessing Responsibility-Based Education (TARE) (Wright \& Craig, 2011) which was used to help the students become more familiar with the terminology and components that should be observed during a TSPR lesson. Using the TARE, the students watched and coded a mock TPSR lesson that had been previously recorded and validated. The students also participated in a typical TPSR lesson that was led by the instructor prior to planning their own lessons. The students explained that the combination of these activities helped to build a better understanding of TPSR and helped prepare them to implement their first lessons with middle school aged students.

The students taught five TPSR based lessons in a middle school, located in a rural area with a high amount of poverty. For the first lessons, the seven college students were divided into groups of two or three and co-taught a TPSR-based lesson to 20-30 middle school students. Changes were made for the remaining lessons due to the lack of management skills and the limited amount of learning taking place. For the rest of the lessons, the college students taught individually in a station-organized format. Each college student prepared a five to seven minute lesson using the TPSR daily format with shortened awareness talks and group meetings. To end the session, the middle school and college students came together for a large group meeting and self-reflection. The group meeting discussion at the end of the session also improved with more students honestly sharing their opinions and experience. On many occasions Hellison has commented on the importance of starting small and always 
keeping things simple. In this study the college students learned first-hand the importance of small and simple.

The findings from this study suggest that learning and implementing TPSR is a "messy" process. Becoming knowledgeable is only step one; implementing a sound TPSR-based lesson and programme takes time and practice. When asked to rate his/her understanding of TPSR, one student stated, "It's one thing to know the model. I can explain TPSR and TARE. However, it's really hard to emphasize and teach the levels (goals) to the kids, especially when they don't do it every day." It was also evident that consistent exposure to the model is important and expecting the middle students to show significant changes in behavior in five sessions was unrealistic. As practitioners, one needs to dedicate sufficient time and resources to develop a supportive learning environment to assist students in becoming personally and socially responsible leaders in and outside of the programme.

Another study examined TPSR implementation with a group of 8 experienced physical education teachers at two different schools. The teachers participated in a year-long professional learning programme aimed at integrating TPSR into their physical education curriculum. The first phase of the professional development included a workshop on the philosophical foundations of TPSR led by well-known scholars in the area. Following the workshop, each teacher had the opportunity to reflect on ways that TPSR may align with their curriculum. During this reflective process, teachers had an opportunity to answer the question "what's worth doing?" (Hellison, 2011) in their physical education programme. Four teachers chose not to emphasize TPSR based on their preferences for a more teachercentered approach. The other four teachers decided that they did value TPSR and opted to engage in a continuing professional development process.

The TARE instruments (Wright \& Craig, 2011) were used to guide the professional development process. Teachers were trained to use the observation instrument and the TARE Post-teaching Reflection (Wright, 2016) was used to assist teachers in reflecting on their own lessons. The four teachers successfully used the TARE instruments to integrate TPSR into their teaching strategies while remaining empowered to decide how TPSR fitted into their school culture. Periodically, a TPSR researcher visited the school to conduct an observation which was then compared to the observations and reflections of the teacher. The TARE tools generated practical data that led to several formal and informal conversations. This research suggests that for some teachers, providing space and time for TPSR implementation along with meaningful data may enhance a TPSR professional learning programme for in-service teachers (Hemphill, Templin, \& Wright, 2015). 
While there are challenges for teachers considering introducing TPSR there have been many teachers who have previously done so successfully. For teachers who are considering introducing TPSR into their practice the following suggestions, based on other teachers' experiences, are offered.

1. Teachers should ensure that they have a good knowledge of TPSR before implementing the programme. This includes an understanding of, and an affinity to, the philosophy that underpins the model, an understanding that will help ensure that the implementation is more than a superficial presentation of the levels. The resources identified previously will allow teachers to gain this knowledge.

2. When developing programmes based on TPSR, teachers give careful consideration to the pedagogical approaches used in the activity segments of the lesson. A successful implementation of TPSR requires students to have opportunities to practice decision-making and to be personally and socially responsible. This means that the classes must be structured in ways that supply these opportunities. It is important, therefore, that appropriate pedagogical approaches be implemented to allow this to occur.

3. When introducing TPSR start with a single class. The programme can be expanded as confidence builds. It is also suggested that teachers start with a movement context which they have full confidence in teaching.

4. Ideas that have been successfully implemented with TPSR classes should be tried with other classes without necessarily implementing the full model. This is done with an understanding that this is not a high fidelity implementation of TPSR but rather an opportunity to share good teaching practices with other students.

5. The importance of the transfer of learning to other contexts should be clearly identified as an important outcome and taught carefully and overtly. This should be explicit, occur right from the start of the implementation and be consistent.

6. Serious consideration should be given to introducing and teaching the goals as being independent rather than as being cumulative. While accepting that treating the goals as cumulative levels has become the norm for many teachers, implementing TPSR as independent goals offers many potential advantages. These include introducing goals when appropriate for the students, removing the belief that four goals need to be met before transfer can be considered and that 
there is a hierarchy of goals where leadership/caring, for example, is of a higher order then respect, self-directed learning or effort.

7. Be aware that the research has shown that most teachers feel unsure at times about what they are doing, especially in the initial stages of any implementation. Teachers should remember, however, that this uncertainty tends to ease as the teacher and the class gets familiar with TPSR. (Gordon, 2010a)

We believe strongly that TPSR offers a valuable way to enrich the physical education experiences of students. It is ideally suited to meet the goals of contemporary physical education and the needs of students as they prepare to live in a rapidly changing world. To help teachers interested in introducing and/or further developing their teaching with TPSR Rick Baldock and Barrie Gordon are forming an Asia-Pacific group that will be aligned with the USA based TPSR Alliance. We would encourage readers to contact either Barrie or Rick via email for further information and to visit the TPSR alliance website.

Barrie Gordon: Barrie.Gordon@ vuw.ac.nz

Rick Baldock: rick@achpersa.com.au

\section{Resources}

When implementing a new pedagogical approach in Physical Education, educators can enhance their work by using evidence informed approaches. When considering TPSR, a rich source of evidence can be gleaned from a number of sources including:

- Hellison, D. (2011). Teaching personal and responsibility through physical activity (3rd ed.). Champaign, IL: Human Kinetics.

- Hellison, D., Cutforth, N., Kallusky, J., Martinek, T., Parker, M., \& Stiehl, J. (2000). Youth development and physical activity: Linking universities and communities. Champaign, IL: Human Kinetics.

- The TPSR Alliance website (http://www.tpsr-alliance.org/): A comprehensive reference list for the Teaching of Personal and Social Responsibility (TPSR) Model that was updated in 2016. The latest version is available at http://www.tpsralliance.org/reference-list.

- The ACHPER Active + Healthy Magazine: In 2016 the Magazine devoted a special issue to the TPSR Model. Dave Walsh edited the issue with a number of excellent contributing writers. The special edition of the magazine (which is free to ACHPER members) can be accessed at: https://www.achper.org.au/associationnews/specialmagazine-issue-teaching-personal-and-social-responsibility. 
- The Journal of Physical Education, Recreation, and Dance (JOPERD): In 2016 JOPERD released a special issue devoted to the TPSR Alliance as a community of practice.

References

ACARA, Health and Physical Education, Structure, Version 8, 2015, cited 16 June, 2017 http://www.australiancurriculum.edu.au/health-and-physical-education/structure

ACARA, , General Capabilities in the Australian Curriculum, Health and Physical Education, Version 8, 2015, cited 16 June, 2017

http://www.australiancurriculum.edu.au/generalcapabilities/overview/learning-areaspecific-advice

Gordon, B. (2010a). Teaching personal and social responsibility through physical education: An examination of the Teaching Personal and Social Responsibility model when taught in a New Zealand secondary school. Saarbrucken:Germany: Lambert Academic Publishing.

Gordon, B., Jacobs, J. M., \& Wright, P. M. (2016). Social and Emotional Learning Through a Teaching Personal and Social Responsibility Based After-School Program for Disengaged Middle-School Boys. Journal of Teaching in Physical Education, 35(4), 358-369.

Gordon, B., Thevenard, L., \& Hodis, F. (2011). A national survey of New Zealand secondary schools physical education programmes implementation of the Teaching Personal and Social Responsibility (TPSR) model. Agora, 14(2), 197-212.

Hellison, D. (2011). Teaching personal and social responsibilty through physical education (3rd ed.). Champaign:IL: Human Kinetics.

Hellison, D., Cutforth, N., Kallusky, J., Martinek, T., Parker, M., \& Stiehi, J. (2000). Youth development and physical activity. Champaign, IL: Human Kinetics.

Hemphill, M. A., Templin, T. J., \& Wright, P. M. (2015. Implementation and outcomes of a responsibility-based continuing professional development protocol in physical education. Sport, Education, and Society, 20(3), 398-419.

Lee, O., \& Choi, E. (2015). The influence of professional development on teachers implementation of the Teaching Personal and Social Responsibility model. Journal of Teaching in Physical Education, 34(4).

Ministry of Education. (2007). The New Zealand Curriculum. Wellington: Learning Media. Walsh, D., Veri, M., \& Willard, J. (2015). Kinesiology career club: Undergraduate student mentors' perspectives on a physical activity-based Teaching Personal and Social Responsibility program. Physical Educator, 72(2), 3017.

Wright, P., \& Craig, M. (2011). Tool for Assessing Responsibility-Based Education (TARE): Instrument Development, Content Validity, and Inter-Rater Reliability. Measurement in Physical Education and Exercise Science, 15(3), 204-219.

Wright, P. M. (2016). Improving TPSR implementation with a structured post-teaching reflection tool. Active and Healthy Magazine, 23(2/3), 12-17. 

educational experience in a sport for development program. Sport, Educatiion and Society, 21(4), 531-548. 